\title{
Anterior spinal artery as a collateral pathway in a case of unilateral vertebrobasilar occlusion: A case report and literature review
}

\author{
Ismail Ibrahim Ismail ${ }^{* *}$ and Ossama Yassin Mansour ${ }^{2}$ \\ ${ }^{1}$ Neurology Specialist, Department of Neurology, Alexandria University, Egypt \\ ${ }^{2}$ Associate Professor, Department of Neurology, Alexandria University, Egypt
}

\begin{abstract}
Background: Vertebral artery (VA) occlusion is an important cause of stroke in the posterior circulation along with basilar artery occlusion. Intracranial VA disease accounts for $21 \%$ of patients with posterior circulation stroke and is bilateral in nearly half of them. Anterior Spinal Artery (ASA) originating from cervical VA to intracranial distal VA and Basilar artery is a possible and infrequent source of collaterals.

Case description: We report a case of acute unilateral vertebral artery occlusion with retrograde flow from ASA as the only collateral pathway reconstituting distal circulation.

Conclusion: Anterior Spinal Artery can play an important role in the setting of unilateral or bilateral vertebral occlusion. Retrograde flow through ASA could reconstitute distal circulation. Adequacy of flow and neurological improvement in this situation depends on the presence of other collateral channels, other vertebral artery and on patency of vertebrobasilar junction.
\end{abstract}

\section{Case report}

A 48 year-old male patient with past medical history of diabetes and hypertension presented to the ER with acute onset of left sided weakness, gait unsteadiness and abnormal speech since 8 hours. Neurological examination showed a conscious, oriented patient with left hemiparesis of Medical Research Council (MRC) grade 3 power, left hemiataxia and staccato speech. National Institutes of Health Stroke Scale (NIHSS) was 13. Initial CT brain was unremarkable.

MRI showed recent infarction involving left cerebellum and left brachium pontis (Figure 1).

The patient was non-eligible for intra-venous thrombolysis and presented to a facility that is not equipped for intra-arterial intervention and received medical treatment in the form of fluids, anti-platelets, anti-hyperlipidemics and neurotonics. Unfortunately the patient
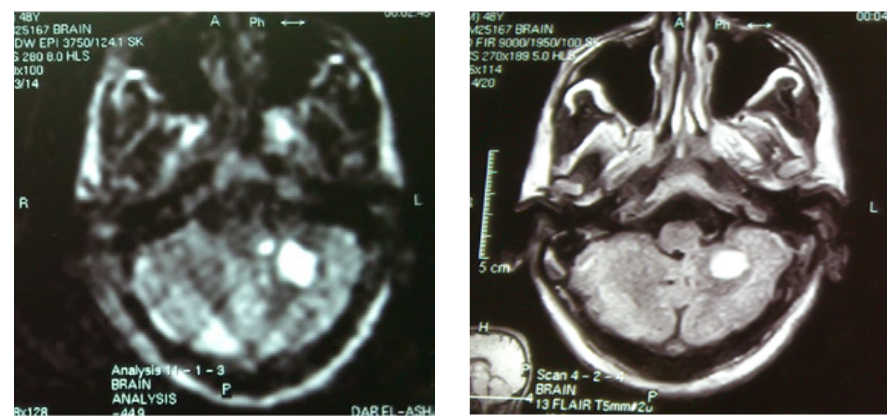

Figure 1. MRI brain (a) DWI showing restricted diffusion of the left cerebellum and left brachium pontis (b) FLAIR showing hyperintense lesion involving left cerebellum with mild perifocal odema. then developed acute onset of quadriplegia, bilateral facial palsy and disturbed sensorium 5 days after the onset of the first stroke and was put on mechanical ventilator. NIHSS was 24 .

Follow up MRI was done and revealed multiple infarctions involving the center of the pons, midbrain and both cerebral peduncles (Figure 2).

The patient was transported to our facility and entered the catheter lab. Digital Subtraction Angiography (DSA) was done revealing the following (Figure 3):

- Total occlusion of the cervical portion of the left vertebral artery with reconstitution of its V4 segment and basilar artery by Anterior Spinal Artery (ASA) through segmental branches with reduced caliber at the origin of the left PICA.

Right vertebral artery showing mild focal segmental stenosis at the proximal portion of its V4 segment and ending as PICA.

Both PCAs showed attenuated caliber with multifocal stenotic segments.

- Normal angiographic features of the anterior circulation.

In our patient, ASA was the only source of collateral supply

Correspondence to: Ismail Ibrahim Ismail, Neurology Specialist, Department of Neurology, Alexandria University, Egypt, E-mail: dr.ismail.ibrahim2012@gmail.com Key words: anterior spinal artery stroke, collateral, vertebrobasilar, steal Received: April 07, 2015; Accepted: May 10, 2015; Published: May 14, 2015 

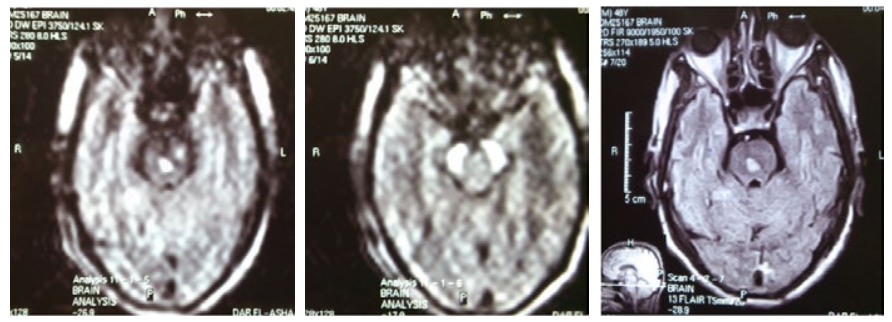

Figure 2. MRI Brain; (a,b) DWI imaging showing restricted diffusion involving center of the pons and bilateral cerebral peduncles, (c) FLAIR showing hyperintense central pontine lesion.
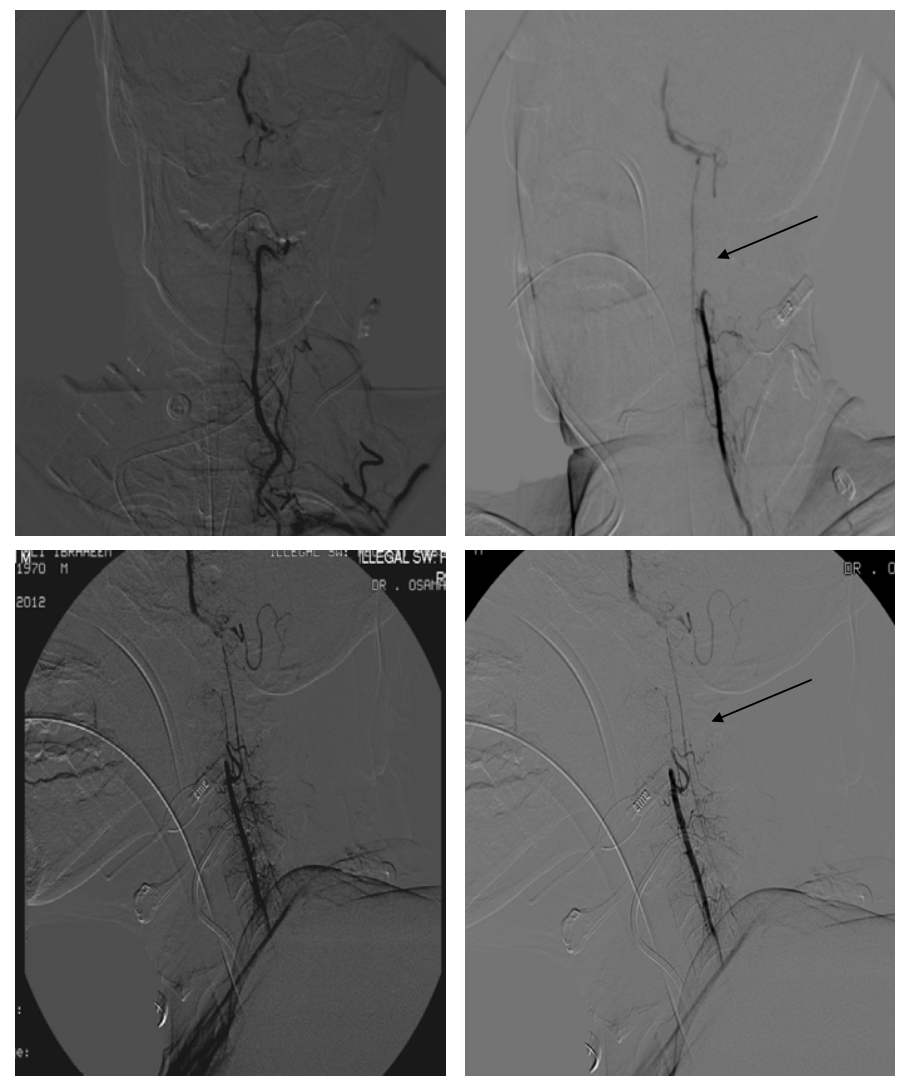

Figure 3. DSA images (a and b: AP view, c and d: Lateral View) showing ASA (arrow) retrogradely filling V4 segment, PICA and basilar artery.

present. It showed a retrograde flow and reconstituted V4 segment of vertebral artery, PICA and basilar artery through segmental branches. Angioplasty to the contralateral VA stenosis was done. The patient's clinical condition stabilized and he was successfully weaned from mechanical ventilator. Other neurological symptoms did not show much improvement because of the late presentation to our facility after his clinical deterioration and due to absence of other collaterals.

\section{Discussion}

Literature review regarding ASA as a source of collateral supply to the posterior circulation showed few case reports [1-3]. The anterior spinal artery originates from VA distal to the PICA as a longitudinal vessels connecting transversely oriented segmental arteries and located on the ventral surface of the cord, adjacent to the ventral median fissure. It varies in size, more or less based on the amount of gray matter at the given segment; its size is substantially larger in the cervical and lumbar segments (around 500-750 micrometers in diameter) as compared with slender mid-thoracic size. The point of origin of ASA is $5-17 \mathrm{~mm}$ proximal to the vertebrobasilar junction. The arterial supply to the ASA consists of radiculomedullary arteries, which represent persistence of embyronic segmental connections between the aorta and the developing ASA. Three types of origin are documented: bilateral origin $(77 \%)$, unilateral origin (10\%), and origin in an intervertebral transverse anastomosis (13\%) [4].

ASA is an important and infrequent source of collateral supply in the setting of bilateral VA occlusion or unilateral occlusion with stenosis of the contralateral VA (as in our patient). Other collaterals in the posterior fossa include Circle of Willis, leptomeningeal collaterals and muscular branches from occipital artery. The degree and extent of perfusion via this collateral channel varies depending on the presence of other collateral routes and patency of the vertebrobasilar junction [5].

Retrograde flow through the anterior spinal artery (ASA) from the cervical vertebral artery (VA) to the intracranial distal VA or basilar artery occurs as a result of hemodynamic vertebrobasilar circulatory insufficiency and defective perfusion. Vertical steal through ASA can be life-saving in cases of posterior circulation stroke but also can cause impairment of spinal long motor and lateral sensory tract functions [6].

Kang et al. reviewed 6 patients with bilateral steno-occlusive disease of vertebral arteries with retrograde flow through ASA and assessed their clinical and angiographic characteristics. Reversal or disappearance of the retrograde flow through ASA was observed after successful recanalization of the occluded VA [7].

Yamakawa et al. also reviewed 2 patients with vertebrobasilar stroke with ASA retrogradely filling ipsilateral PICA and treated with drip intravenous infusion of edaravone and/or argatroban. One patient showed complete recovery due to functioning Pcom, while the other lapsed into coma [8].

In our patient, ASA was the only source of collateral supply showing a retrograde flow and reconstituted V4 segment of vertebral artery, PICA and basilar artery through segmental branches. Although the neurological insult was severe, ASA played a pivotal role in our patient and his condition stabilized afterward and he was successfully weaned from mechanical ventilator.

\section{Conclusion}

We report a case of acute unilateral vertebrobasilar stroke with ASA as the only source of collateral supply. Retrograde flow through ASA reconstituted distal circulation. Adequacy of flow and neurological improvement in this situation depends on the presence of other collateral channels, other vertebral artery and on patency of vertebrobasilar junction.

\section{References}

1. Uchiyama S, Yoshida M, Shimizu H (1995) MR imaging of the anterior spinal artery in a case of bilateral vertebral arterial occlusion. Rinsho Shinkeigaku 35: 60-63. [Crossref]

2. Garnier P, Januel AC, Demasles S, Michel D (2003) Collateralization of vertebral arteries. Neurology 60: 720. [Crossref]

3. Hott JS, Vishteh G, Wallace R, Dean BL, Spetzler RF (2004) Anterior spinal artery supplying posterior circulation. Neurology 62: 468. [Crossref]

4. Lasjaunias P, Berenstein A, Brugge KG (2001) Clinical Vascular Anatomy and Variations, in Surgical Neuroangiography, Lasjaunias P (Ed), Springer, 110-50.

5. Shin HK, Yoo KM, Chang HM, Caplan LR (1999) Bilateral intracranial vertebral artery disease in the New England Medical Center, Posterior Circulation Registry. Arch Neurol 56: 1353-58. [Crossref] 
Ismail II (2015) Anterior spinal artery as a collateral pathway in a case of unilateral vertebrobasilar occlusion: A case report and literature review

6. Darwish H, Archer C, Modin J (1979) The anterior spinal artery collateral in coarctation of the aorta. A clinical angiographic correlation. Arch Neurol 36: 240-243. [Crossref]

7. Kang HS, Han MH, Kim SH, Kwon OK, Roh HG, et al. (2007) Anterior spinal artery as a collateral channel in cases of bilateral vertebral arterial steno-occlusive diseases. AJNR Am J Neuroradiol 28: 222-225. [Crossref]

8. Yamakawa H, Yoshimura S, Iwama T (2009) Anterior spinal artery as a collateral channel in patients with acute bilateral vertebral artery occlusions. Two case reports. Neurol Med Chir (Tokyo) 49: 354-358. [Crossref]

Copyright: (C2015 Ismail II. This is an open-access article distributed under the terms of the Creative Commons Attribution License, which permits unrestricted use, distribution, and reproduction in any medium, provided the original author and source are credited. 